\title{
Analysis of postoperative morbidity and mortality following surgery for gastric cancer. Surgeon volume as the most significant prognostic factor
}

\author{
Maciej Ciesielski ${ }^{1,2}$, Wiesław J. Kruszewski ${ }^{1,2}$, Jakub Walczak ${ }^{1}$, Mariusz Szajewski ${ }^{1,2}$, Jarosław Szefel ${ }^{1,2}$, \\ Jacek Wydra ${ }^{1}$, Tomasz Buczek ${ }^{1}$, Maksymilian Czerepko ${ }^{1}$ \\ ${ }^{1}$ Department of Oncological Surgery, Gdynia Oncology Centre, Gdynia, Poland \\ ${ }^{2}$ Division of Propaedeutics of Oncology, Medical University of Gdansk, Gdansk, Poland
}

Gastroenterology Rev 2017; 12 (3): 215-221

DOI: https://doi.org/10.5114/pg.2017.70475

Key words: gastric cancer, gastrectomy, morbidity, mortality, risk factor.

Address for correspondence: Maciej Ciesielski MD, PhD, Department of Oncological Surgery, Gdynia Oncology Centre, 31 a Przebendowskich St, 81-526 Gdynia, Poland, phone: +48 608531 884, e-mail: maccies@gumed.edu.pl

\begin{abstract}
Introduction: Surgical resection is the only potentially curative modality for gastric cancer and it is associated with substantial morbidity and mortality.

Aim: To determine risk factors for postoperative morbidity and mortality following major surgery for gastric cancer.

Material and methods: Between 1.08.2006 and 30.11.2014 in the Department of Oncological Surgery of Gdynia Oncology Centre 162 patients underwent gastric resection for adenocarcinoma. All procedures were performed by 13 surgeons. Five of them performed at least two gastrectomies per year $(n=106)$. The remaining 56 resections were done by eight surgeons with annual volume lower than two. Perioperative mortality was defined as every in-hospital death and death within 30 days after surgery. Causes of perioperative deaths were the matter of in-depth analysis.

Results: Overall morbidity was $23.5 \%$, including $4.3 \%$ rate of proximal anastomosis leak. Mortality rate was $4.3 \%$. Morbidity and mortality were not dependent on: age, gender, body mass index, tumour location, extent of surgery, splenectomy performance, or pTNM stage. The rates of morbidity ( $50 \%$ vs. $21.3 \%$ ) and mortality (16.7\% vs. $3.3 \%)$ were significantly higher in cases of tumour infiltration to adjacent organs (pT4b). Perioperative morbidity and mortality were $37.5 \%$ and $8.9 \%$ for surgeons performing less than two gastrectomies per year and $16 \%$ and $0.9 \%$ for surgeons performing more than two resections annually. The differences were statistically significant $(p=0.002, p=0.003)$.

Conclusions: Annual surgeon case load and adjacent organ infiltration (pT4b) were significant risk factors for morbidity and mortality following major surgery for gastric cancer. The most common complications leading to perioperative death were cardiac failure and proximal anastomosis leak.
\end{abstract}

\section{Introduction}

Gastric cancer in the USA and Europe is a disease of declining incidence, induced mainly by external factors, and with peak incidence in the $7^{\text {th }}$ decade of life [1]. The prognosis in advanced cases is poor and overall 5 -year survival does not exceed $30 \%$. The only potentially curative modality is surgical resection $[1,2]$. Patients continue to be diagnosed with an advanced stage and require multimodality therapy planning [3]. They are often in advanced age and present serious comorbidities. Major surgery in such settings is associated with substantial morbidity and mortality [4]. Patient selection for surgery is often difficult for both the surgeon and the anaes- thesiologists. Serious complications following surgery are likely to delay adjuvant therapy, and may negatively impact overall survival and increase costs [2].

\section{Aim}

The aim of the study was to determine the risk factors for morbidity and mortality following gastrectomy for cancer on the basis of our own experience.

\section{Material and methods}

Between 1.08.2006 and 30.11.2014 in our department 162 patients underwent gastric resection for adenocarcinoma. The medical records and histopathological 
reports were retrospectively reviewed. We performed 141 total gastrectomies (87\%) and 21 subtotal or partial stomach resections. The rate of palliative resections was $24 \%$. Preoperative total parenteral nutrition was necessary in 28 (17.3\%) patients. All procedures were performed by a group of 13 surgeons. Five of them performed at least two gastrectomies per year $(n=106)$. The remaining 56 resections were done by eight surgeons with annual volume lower than two. In case of total gastrectomy, proximal end-to-side anastomosis was done between the oesophagus and jejunum with a circular stapling device. The Roux-en-Y method was the reconstruction of choice. Intraoperatively, we routinely checked the integrity of proximal anastomosis for air leak by a "Jacuzzi" test. A water-soluble contrast swallow test was routinely performed on the seventh postoperative day, before commencing oral intake. Partial and subtotal resections were followed by a hand-sutured or stapler Billroth II gastrojejunostomy

Table I. Complications characteristics and causes of perioperative mortality

\begin{tabular}{|c|c|c|}
\hline Complication type & Frequency & $\begin{array}{c}\text { Perioperative } \\
\text { mortality }\end{array}$ \\
\hline Total: & $38(23.5 \%)$ & $7(4.3 \%)$ \\
\hline Surgical: & $26(16.0 \%)$ & $3(1.9 \%)$ \\
\hline Leakage: & $11(6.8 \%)$ & - \\
\hline Proximal & $7(4.3 \%)$ & $2(1.2 \%)$ \\
\hline Duodenal stump & $2(1.2 \%)$ & - \\
\hline Jejuno-jejunal & $2(1.2 \%)$ & - \\
\hline SSI: & $7(4.3 \%)$ & - \\
\hline Deep & $3(1.9 \%)$ & $1(0.6 \%)$ \\
\hline Superficial & $4(2.5 \%)$ & - \\
\hline Late anastomotic stricture & $2(1.2 \%)$ & - \\
\hline Acute pancreatitis & $1(0.6 \%)$ & - \\
\hline $\begin{array}{l}\text { Bile leak (after } \\
\text { cholecystectomy) }\end{array}$ & $1(0.6 \%)$ & - \\
\hline Anastomotic bleeding & $1(0.6 \%)$ & - \\
\hline Peritoneal bleeding & $1(0.6 \%)$ & - \\
\hline Eventration & $1(0.6 \%)$ & - \\
\hline latrogenic colon perforation & $1(0.6 \%)$ & - \\
\hline Medical: & $12(7.4 \%)$ & $4(2.5 \%)$ \\
\hline Cardiac & $6(3.7 \%)$ & $4(2.5 \%)$ \\
\hline Pulmonary & $5(3.1 \%)$ & - \\
\hline Urinary tract infection & $1(0.6 \%)$ & - \\
\hline
\end{tabular}

or Roux-en-Y reconstruction according to the surgeon's preference, and integrity tests were not performed. For statistical reasons we divided complications into surgical or medical. Pathologic stages were determined according to the seventh edition of the International Union Against Cancer classification [5]. We combined stages 0-II and III-IV into two separate groups. Because most pT stage distribution was similar in the compared groups and the differences were only seen in cases of pT4b, we decided to distinguish infiltration of adjacent organs as a feature that might have an impact on morbidity and mortality. Perioperative mortality was defined as every death during the same hospitalisation and death occurring within 30 days after surgery. Causes of perioperative death were the matter of in-depth analysis. In calculations concerning mean and median postoperative hospital stay we excluded patients who did not survive 30 days postoperatively or died due to complications before discharge.

\section{Statistical analysis}

All statistical analyses were performed using Statistica (data analysis software system, version 10 , StatSoft Inc. 2011). Comparisons were made with $\chi^{2}$ Pearson and $U$ Mann-Whitney tests, as appropriate. A logistic regression model was built to perform multivariate analysis and identify variables independently associated with morbidity and mortality. $P$-value was considered significant if less than 0.05 .

\section{Results}

Over half $(57.1 \%)$ of postoperative deaths were caused by cardiac complications. Two other cases (28.6\%) were due to proximal anastomosis leak, and one patient died on the $56^{\text {th }}$ postoperative day due to cachexia and sepsis in the course of intra-abdominal abscess in the space left after splenectomy (Table I). Proximal anastomosis leaks were treated conservatively with good results in two cases, and in the remaining five by early relaparotomy. Time of postoperative hospital stay in complicated cases was significantly longer (mean 35.7 vs. 9 days, median 18 vs. 9), $p=0.0001$.

Comparison of continuous variables such as age, body mass index (BMI), harvested and metastatic lymph node numbers dependent of complications, and perioperative death occurrence is shown in Table II. We noted significantly fewer median lymph nodes harvested in the group of patients that died perioperatively.

Morbidity and mortality rates in relation to gender, type and intention of surgery, depth of tumour infiltration, lymph node status, presence of distant metastases, pTNM stage, tumour localisation, performed splenectomy, necessity for preoperative total parenteral 
Table II. Comparison of age, BMI, harvested and metastatic lymph node numbers dependent of complications, and perioperative death occurrence

\begin{tabular}{|c|c|c|c|c|c|c|c|}
\hline Parameter & $\begin{array}{c}\text { Total } \\
(n=162)\end{array}$ & $\begin{array}{l}\text { Complicated } \\
\qquad(n=38)\end{array}$ & $\begin{array}{c}\text { Non- } \\
\text { complicated } \\
(n=124)\end{array}$ & $P$-value & $\begin{array}{l}\text { In hospital or } \\
\text { 30-day mortality } \\
(n=7)\end{array}$ & $\begin{array}{l}\text { Survivors } \\
(n=155)\end{array}$ & $P$-value \\
\hline $\begin{array}{l}\text { Mean age (median) } \\
\text { [years] }\end{array}$ & $66.8(68)$ & $68.3(72)$ & $66.4(67)$ & NS & $67.0(71)$ & $66.8(68)$ & NS \\
\hline $\begin{array}{l}\text { Mean BMI (median) } \\
{\left[\mathrm{kg} / \mathrm{m}^{2}\right]}\end{array}$ & $24.9(24.2)$ & $23.3(21.9)$ & $25.3(25.0)$ & NS & $22.3(22.3)$ & $25.1(24.2)$ & NS \\
\hline $\begin{array}{l}\text { Mean number of } \\
\text { harvested lymph } \\
\text { nodes (median) }\end{array}$ & $18.6(17.5)$ & $16.4(14)$ & $19.2(18)$ & NS & $9.0(9)$ & $19.0(18)$ & 0.006 \\
\hline $\begin{array}{l}\text { Mean number of } \\
\text { metastatic lymph } \\
\text { nodes (median) }\end{array}$ & $4.9(2)$ & $3.9(1)$ & $5.2(2)$ & NS & $1.9(0)$ & $5.0(2)$ & NS \\
\hline
\end{tabular}

nutrition, and neoadjuvant chemotherapy are presented in Table III. The only factor significantly associated with morbidity and mortality was adjacent organ infiltration (pT4b). The invaded organs were pancreas $(n=6)$, liver $(n=3)$, transverse colon or mesocolon $(n=2)$, and spleen $(n=1)$. Radical multivisceral en bloc surgery was performed in 5 cases, and the remaining seven pT4b procedures were palliative. None of the pT4b patients underwent neoadjuvant chemotherapy.

Table IV demonstrates the differences in surgery outcomes dependent on the surgeon's annual case load. Patients operated by surgeons performing less than two gastrectomies per year were associated with more frequent distant metastases or peritoneal spread. Other clinicopathological parameters such as age, BMI, depth of tumour infiltration, tumour location, and pTNM stage were similar in both groups. Procedures performed by lower volume surgeons were associated with significantly higher rates of surgical and overall morbidity and perioperative mortality. There were no significant differences concerning rates of splenectomy, medical complications, redo surgeries, blood transfusion, and numbers of harvested lymph nodes. In multivariate analysis, adjacent organ invasion was an independent prognostic factor for morbidity $(p=0.03)$ and surgeon volume was an independent prognostic factor for both morbidity $(p=0.003)$ and mortality $(p=0.02)$.

\section{Discussion}

Lepage et al. analysed early and late results of gastric cancer surgery in seven European countries. In univariate analysis, perioperative mortality was associated with advanced age, proximal tumour location, total gastrectomy, and higher stage at diagnosis. The rates of mortality were also significantly different between countries, being highest (16\%) in Poland [6]. In the unicentre study by Persiani et al. the factors associated with postoperative morbidity were: age over 64 years, performance of splenectomy or other adjacent organ resection and, extended (D2) limfadenectomy. Although multivisceral resection in cases of suspicion of adjacent organs invasion was associated with a three-fold higher rate of perioperative mortality, the difference was not statistically significant [7]. Similar factors predictive of postoperative morbidity and mortality were revealed in other series $[4,8,9]$. Less frequently demonstrated factors associated with morbidity and mortality were: comorbidities [8], male gender [10], hypoalbuminaemia [4], and preoperative body mass loss [4]. In our study, perioperative death was associated with less lymphatic harvest, most likely due to higher medical risk or more advanced stage found in preoperative assessment, which resulted in a limited extent of surgery in these patients. Another explanation could be that these patients were operated by lower volume surgeons tending to perform less extent of lymphadenectomy. However, these hypotheses cannot be proven by available data. Other relationships concerning determinants of morbidity and mortality were similar to those revealed by other authors, but the statistical significance was achieved only for adjacent organ infiltration (Tables II and III).

Increased risk of postoperative morbidity in the case of adjacent organ invasion and performance of multivisceral resection was also demonstrated by $\mathrm{Pa}$ penfuss et al. The authors point out that patients with serious complications are less likely to receive adjuvant treatment, which may negatively impact the survival [4]. Inferior survival outcomes linked to postoperative morbidity were demonstrated in other papers [11]. The frequency of postoperative complications in pT4b cases reaching $50 \%$ suggests withdrawal from resection in favour of neoadjuvant chemotherapy, although the benefits of such practise are still the matter of discussion. In cases of gastric cancer significant discrepancies 
Table III. Morbidity and mortality dependent on gender, type and intention of surgery, depth of tumour infiltration, lymph node status, presence of distant metastases, PTNM, tumour localisation, performed splenectomy, necessity for preoperative total parenteral nutrition (TPN), and neoadjuvant chemotherapy

\begin{tabular}{|c|c|c|c|c|}
\hline Parameter & Morbidity (\%) & $P$-value & Mortality (\%) & $P$-value \\
\hline \multicolumn{5}{|l|}{ Gender: } \\
\hline Male, $n=108$ & 24.1 & \multirow[t]{2}{*}{ NS } & 2.8 & \multirow[t]{2}{*}{ NS } \\
\hline Female, $n=54$ & 22.2 & & 7.4 & \\
\hline \multicolumn{5}{|l|}{ Type of surgery: } \\
\hline Gastrectomy $(n=141)$ & 23.4 & \multirow[t]{2}{*}{ NS } & 4.3 & \multirow[t]{2}{*}{ NS } \\
\hline Subtotal or partial resection $(n=21)$ & 23.8 & & 4.8 & \\
\hline \multicolumn{5}{|l|}{ Surgery intention: } \\
\hline Radical $(n=123)$ & 22.8 & \multirow[t]{2}{*}{ NS } & 4.1 & \multirow[t]{2}{*}{ NS } \\
\hline Palliative $(n=39)$ & 25.6 & & 5.1 & \\
\hline \multicolumn{5}{|l|}{ Depth of invasion: } \\
\hline pTis-pT4a $(n=150)$ & 21.3 & \multirow[t]{2}{*}{0.02} & 3.3 & \multirow[t]{2}{*}{0.02} \\
\hline pT4b $(n=12)$ & 50 & & 16.7 & \\
\hline \multicolumn{5}{|l|}{ Lymph node status: } \\
\hline Positive $(n=102)$ & 23.5 & \multirow[t]{2}{*}{ NS } & 2.9 & \multirow[t]{2}{*}{ NS } \\
\hline Negative $(n=60)$ & 23.3 & & 6.7 & \\
\hline \multicolumn{5}{|l|}{ Distant metastases: } \\
\hline MO $(n=140)$ & 23.6 & \multirow[t]{2}{*}{ NS } & 3.6 & \multirow[t]{2}{*}{ NS } \\
\hline $\mathrm{M} 1(n=22)$ & 22.7 & & 9.1 & \\
\hline \multicolumn{5}{|l|}{ pTNM: } \\
\hline $0-11(n=74)$ & 20.3 & \multirow[t]{2}{*}{ NS } & 4.1 & \multirow[t]{2}{*}{ NS } \\
\hline III-IV $(n=88)$ & 26.1 & & 4.6 & \\
\hline \multicolumn{5}{|l|}{ Tumour localisation: } \\
\hline Cardia $(n=44)$ & 31.8 & \multirow[t]{2}{*}{ NS } & 6.8 & \multirow[t]{2}{*}{ NS } \\
\hline Other $(n=118)$ & 20.3 & & 3.4 & \\
\hline \multicolumn{5}{|l|}{ Splenectomy: } \\
\hline Yes $(n=23)$ & 34.8 & \multirow[t]{2}{*}{ NS } & 8.7 & \multirow[t]{2}{*}{ NS } \\
\hline No $(n=139)$ & 21.6 & & 3.6 & \\
\hline \multicolumn{5}{|l|}{ Preoperative TPN: } \\
\hline Yes $(n=28)$ & 35.7 & \multirow[t]{2}{*}{ NS } & 3.6 & \multirow[t]{2}{*}{ NS } \\
\hline No $(n=134)$ & 20.9 & & 4.5 & \\
\hline Neoadjuvant: & & & & \\
\hline Yes $(n=11)$ & 18.2 & NS & 0 & NS \\
\hline No $(n=151)$ & 23.8 & & 4.6 & \\
\hline
\end{tabular}


between preoperative imaging and intraoperative findings are not uncommon. According to our experience, diagnostic laparoscopy is an excellent tool for both macro- and microscopic peritoneal spread detection, but the procedure does not always allow us to recognise transmural invasion of adjacent organs. Currently in both European and American guidelines adjuvant treatment is recommended as the best approach in all mid-stage gastric cancers and curative treatment intent $[1,3]$. On the other hand, Korean authors reporting the outcomes of 243 radical multivisceral resections for pT4b gastric cancer without neoadjuvant treatment achieved 5-year survival at the unattainable in Western settings rate of $36.8 \%$ with $15 \%$ postoperative morbidity and $2 \%$ mortality. They concluded that only patients with pancreatic head invasion, para-aortic nodes involvement, or distant metastases were unsuitable for the primary resection [12]. Other Asiatic authors also promote multivisceral resections in pT4b tumours $[9,13,14]$, in spite of relatively high postoperative morbidity rates (28.0-55.6\%). Unfortunately, randomised studies in this matter are unavailable.

The vast majority of patients diagnosed with gastric cancer in the West are over 60 years old. The median age of our patients was 68 years. Patients at this age often suffer from serious comorbidities. In the literature, the principal causes of death following gastrectomy for cancer are respiratory infections and failure, cardio-vascular problems, and sepsis as a consequence of anastomotic dehiscence. Rare incidence of atherosclerotic heart disease and quite young age of diagnosed patients in Japan are thought to be at least partly responsible for the superior mortality results in this country [15]. In the present study, more than half of the postoperative deaths were caused by complications of a cardio-vascular nature. Pulmonary complications were almost equally often but they were not lethal in any case. In the unicentre study by Gong et al. cardio-vascular complications were the cause of three out of four postoperative deaths in a group of 125 patients undergoing gastrectomy for cancer [8]. Since it is not possible to guarantee an uneventful postoperative course, appropriate counselling regarding the true risks and benefits of proposed surgery in patients with serious comorbidities is highly recommended [2].

Oesophagojejunal anastomosis failure is one of the most serious complications associated with upper gastrointestinal surgery [16]. In our study it was the second leading cause of postoperative death (28.6\%). In other series it was also one of the main causes of postoperative mortality $[10,16,17]$. Two of 7 of our patients with proximal anastomosis leak died (28.6\%). In other studies mortality among patients with this
Table IV. Patient characteristics and surgery outcome in reference to surgeon annual volume

\begin{tabular}{|c|c|c|c|}
\hline Parameter & $\begin{array}{l}\text { Lower- } \\
\text { volume } \\
\text { surgeon } \\
(n=56)\end{array}$ & $\begin{array}{l}\text { Higher- } \\
\text { volume } \\
\text { surgeon } \\
(n=106)\end{array}$ & $P$-value \\
\hline $\begin{array}{l}\text { Mean age } \\
\text { (median) }\end{array}$ & $67.3(69)$ & $66.6(68)$ & NS \\
\hline $\begin{array}{l}\text { Mean BMI } \\
\text { (median) }\end{array}$ & $23.7(22.5)$ & $25.4(25)$ & NS \\
\hline $\begin{array}{l}\text { Tumour location } \\
\text { (cardia rate) }\end{array}$ & $30.4 \%$ & $25.5 \%$ & NS \\
\hline pT4b rate & $8.9 \%$ & $6.6 \%$ & NS \\
\hline $\begin{array}{l}\text { Mean number of } \\
\text { metastatic nodes } \\
\text { (median) }\end{array}$ & $4.7(1.5)$ & $5.0(2)$ & NS \\
\hline $\begin{array}{l}\text { Distant } \\
\text { metastases }\end{array}$ & $25 \%$ & $7.5 \%$ & 0.002 \\
\hline pTNM III-IV rate & $60.7 \%$ & $50.9 \%$ & NS \\
\hline Complication rate: & $37.5 \%$ & $16.0 \%$ & 0.002 \\
\hline Surgical & $26.8 \%$ & $10.4 \%$ & 0.006 \\
\hline Redo surgery & $16.1 \%$ & $7.5 \%$ & NS \\
\hline General & $10.7 \%$ & $5.7 \%$ & NS \\
\hline $\begin{array}{l}\text { Perioperative } \\
\text { deaths }\end{array}$ & $10.7 \%$ & $0.9 \%$ & 0.003 \\
\hline $\begin{array}{l}\text { Mean number of } \\
\text { harvested nodes } \\
\text { (median) }\end{array}$ & $17.5(17)$ & $19.1(18)$ & NS \\
\hline Splenectomy & $16.1 \%$ & $21.7 \%$ & NS \\
\hline $\begin{array}{l}\text { Mean erythrocyte } \\
\text { mass units } \\
\text { (median) }\end{array}$ & $3.0(2)$ & $2.4(2)$ & NS \\
\hline Postoperative stay & 14.7 (9) & $14.1(9)$ & NS \\
\hline
\end{tabular}

feared problem varied between $21.7 \%$ and $46 \%$ [ 10 , $16,17]$. Early diagnosis and quick implementation of proper treatment are the major concerns. The treatment of choice is re-operation and repair, but it is possible only early after primary surgery and when the patient is stabilised. The results of redo surgery in established sepsis associated with ongoing leakage are much worse because of inflammatory adhesions, the friability of the tissues, and the poor wound healing associated with inflammatory response to infection and trauma [15]. That is why in cases of late diagnosis conservative treatment remains the best approach. It is managed by the placement of a naso-jejunal tube for aspiration, ultrasonography-guided drainage of intra-abdominal collections, broad-spectrum antibiotics, parenteral nutrition, and enteral feeding by a tube placed a significant distance 
below the site of dehiscence. It should be noted that conservative treatment is also burdened with high risk of failure. However, not all researchers prefer re-operation in case of early diagnosed anastomotic leakage. Lang et al. state that redo surgery should only be considered in cases of failure of conservative treatment. They reported $19 \%$ mortality among patients treated conservatively and $64 \%$ mortality in cases of surgical management. The authors point out that the groups treated surgically and conservatively were not comparable because the re-operations were performed only in cases of conservative treatment failure, so re-operated patients represented a negative selection [18]. In our opinion, such high mortality among patients undergoing redo surgery could partly result from the delay in surgery performance. In our experience, conservative treatment was successfully performed in 2 cases, while among the remaining five treated surgically, mortality was $40 \%$. In spite of such results we consider early re-operation as a treatment of choice in case of leak diagnosis before the fourth postoperative day. A similar strategy has been proposed by Sarela et al. after oesophagectomy for cancer; however, the borderline for surgical management of anastomotic leak was postoperative day 5 [19]. Another promising method of anastomotic failure management is endoscopic self-expandable metal stent placement [20-22].

Current gastric cancer treatment guidelines emphasise the necessity of multidisciplinary planning and the principal role of the surgeon expected to provide speciality expertise to optimise the outcome [3]. Many studies proved significant relationships between the number of annually performed gastrectomies and the treatment outcome [23]. However, the exact surgeon annual volume providing the optimal results has not been specified. It is generally believed that hospital volume is more important that individual surgeon volume $[24,25]$. The mean annual volume in our study was 19.2. The number does not include stomach resections for lymphomas, GISTs, neuroendocrine tumours, and multivisceral resections for reasons other than gastric adenocarcinoma. Hannan et al. in their comparative study concerning in-hospital mortality for gastrectomy and other cancer procedures demonstrated that $25 \%$ of gastric resections were performed by surgeons within annual case load less than one, and only $25 \%$ of procedures were done by surgeons that performed at least 12 gastrectomies during the 4-year study period. The elite group of the 41 highest volume surgeons among a total of 1114 , performed six gastrectomies per year. The significant difference in postoperative mortality was in favour of the highest volume surgeons (2.76\% vs. 8.83\%) [23]. In another paper by de Gara et al., only four among 84 surgeons performed more than 20 gastrectomies during the 7 -year study period, and 70 surgeons performed less than 10 [26]. In North America and Europe the vast majority of gastric cancer patients are operated by low-volume surgeons, unlike in Asiatic countries. In comparative analysis concerning survival after radical gastrectomy by Chinese authors, surgeons recognised as specialised in oncological gastrectomy were defined as: from the Department of Gastric Cancer, who had undergone professional training in Japan, and with an annual individual volume of more than 50 . Specialised surgeons achieved significantly superior 5-year survival. The authors did not find differences in perioperative morbidity and mortality [27]. Another interesting analysis was published by Gil-Rendo et al. The authors divided surgeons performing gastrectomies for cancer into four categories according to their experience. The highest experience (more than 10 years of experience in gastric cancer surgery) was associated with the highest postoperative morbidity. It was concluded that more advanced tumours and patients with serious risk factors were operated by surgeons with more experience; however, the authors did not demonstrate data to confirm this hypothesis [10].

Patients operated by lower-volume surgeons in our study were associated with more frequent presence of distant metastases or peritoneal spread (Table IV). Initially we could not explain this finding. However, similar relationships were demonstrated by other authors [25, 26]. Bachmann et al. conclude that patients thought to have a poor prognosis tend to be referred to low-volume surgeons [25]. Until now, we have not been aware of such a tendency. We can see from analysis of data from Table IV that patients operated by lower-volume surgeons also tended to present lower $\mathrm{BMI}$, higher rate of tumours located in the cardia, and higher rate of adjacent organs invasion. These differences, however, did not reach the level of statistical significance.

Some limitation of the study is the lack of data concerning patient comorbidities. However, a reliable collection of these data and their proper categorisation in order to perform statistical analysis on the basis of archival records could be deficient and misleading, so they were not included into the current analysis.

\section{Conclusions}

The surgeon remains a significant predictive factor of morbidity and mortality following gastrectomy for cancer. Analysis of our material demonstrates that surgeons from the oncological centre performing about 20 gastrectomies per year, and with individual annual volume more than two becomes a guarantee of 
superior outcomes in comparison with lower-volume surgeons. Comparing the results of lower- versus higher-volume surgeon, patient selection should be taken into account. Patients with locally advanced tumours requiring multivisceral resection ( $\mathrm{pT} 4 \mathrm{~b})$ are at higher risk of postoperative morbidity and mortality.

\section{Conflict of interest}

The authors declare no conflict of interest.

\section{References}

1. Waddell T, Verheij M, Allum W, et al. Gastric cancer: ESMO-ESSOESTRO clinical practice guidelines for diagnosis, treatment and follow-up. Ann Oncol 2013; 24 (Suppl. 6): vi57-63.

2. Papenfuss WA, Kukar M, Oxenberg J, et al. Morbidity and mortality associated with gastrectomy for gastric cancer. Ann Surg Oncol 2014; 21: 3008-14.

3. Schwarz RE. Current status of management of malignant disease: current management of gastric cancer. J Gastrointest Surg 2015; 19: 782-8.

4. Bartlett EK, Roses RE, Kelz RR, et al. Morbidity and mortality after total gastrectomy for gastric malignancy using the American College of Surgeons National Surgical Quality Improvement Program database. Surgery 2014; 156: 298-304.

5. Sobin LH, Gospodarowicz MK, Wittekind C. International union against cancer (UICC) TNM classification of malignant tumors. $7^{\text {th }}$ ed. Wiley-Liss, New York 2010.

6. Lepage C, Sant M, Verdecchia A, et al. Operative mortality after gastric cancer resection and long-term survival differences across Europe. Br J Surg 2010; 97: 235-9.

7. Persiani R, Antonacci V, Biondi A, et al. Determinants of surgical morbidity in gastric cancer treatment. J Am Coll Surg 2008; 207: 13-9.

8. Gong DJ, Miao CF, Bao Q, et al. Risk factors for operative morbidity and mortality in gastric cancer patients undergoing total gastrectomy. World J Gastroenterol 2008; 14: 6560-3.

9. Lee KG, Lee HJ, Yang JY, et al. Risk factors associated with complications following gastrectomy for gastric cancer: retrospective analysis of prospectively collected data based on the Clavien-Dindo system. J Gastrointest Surg 2014; 18: 1269-77.

10. Gil-Rendo A, Hernandez-Lizoain JL, Martinez-Regueira F, et al. Risk factors related to operative morbidity in patients undergoing gastrectomy for gastric cancer. Clin Tranl Oncol 2006; 8: 354-61.

11. Tokunaga M, Tanizawa Y, Bando E, et al. Poor survival rate in patients with postoperative intra-abdominal infectious complications following curative gastrectomy for gastric cancer. Ann Surg Oncol 2013; 20: 1575-83.

12. Min JS, Jin SH, Park S, et al. Prognosis of curatively resected pT4b gastric cancer with respect to invaded organ type. Ann Surg Oncol 2012; 19: 494-501.

13. Khar D, Kubota H, Tachibana M, et al. Prognosis of T4 gastric carcinoma patients: an appraisal of aggressive surgical treatment. J Surg Oncol 2001; 76: 278-82.

14. Kobayashi A, Nakagohri T, Konishi M, et al. Aggressive surgical treatment for T4 gastric cancer. J Gastrointest Surg 2004; 8: 464-70.
15. McCulloch P. The role of surgery in patients with advanced gastric cancer. Best Pract Res Clin Gastroenterol 2006; 20 : 767-87.

16. Sierzega M, Kolodziejczyk P, Kulig J; the Polish Gastric Cancer Study Group. Impact of anastomotic leakage on long-term survival after total gastrectomy for carcinoma of the stomach. Br J Surg 2010; 97: 1035-42.

17. Nathankumaran S, Fernandes E, Thompson AM, et al. Morbidity and mortality rates following gastric cancer surgery and contiguous organ removal, a population-based study. Eur J Surg Oncol 2005; 31: 1141-4.

18. Lang H, Piso P, Stukenborg C, et al. Management and results of proximal anastomotic leaks in a series of 1114 total gastrectomies for gastric carcinoma. Eur J Surg Oncol 2000; 26: 168-71.

19. Sarela AI, Tolan DJ, Harris K, et al. Anastomotic leakage after esophagectomy for cancer: a mortality-free experience. J Am Coll Surg 2008; 206: 516-23.

20. Sampaio JA, Waechter FL, Pereira-Lima J, et al. Successful treatment of esophagojejunal disconnection after total gastrectomy by insertion of a covered self-expandable esophageal metallic stent. Gastrointest Endosc 2003; 58: 453-6.

21. Raimondo D, Sinagra E, Facella T, et al. Self-expandable metal stent placement for closure of a leak after total gastrectomy for gastric cancer: report on three cases and review of the literature. Case Rep Gastrointest Med 2014; 2014: 409283.

22. Facy O, Goergen M, Poulain V, et al. Minimally invasive management of postoperative esophagojejunal anastomotic leak. Surg Laparosc Endosc Percutan Tech 2014; 24: 183-6.

23. Hannan EL, Radzyner M, Rubin D, et al. The influence of hospital and surgeon volume on in-hospital mortality for colectomy, gastrectomy, and lung lobectomy in patients with cancer. Surgery 2002; 131: 6-15.

24. Meyer HJ. The influence of case load and the extent of resection on the quality of treatment outcome in gastric cancer. Eur J Surg Oncol 2005; 31: 595-604.

25. Bachmann MO, Anderson D, Edwards S, et al. Cohort study in South and West England of the influence of specialization on the management and outcome of patients with oesophageal and gastric cancers. Br J Surg 2002; 89: 914-22.

26. de Gara C, Hanson J, Hamilton S. A population-based study of tumor-node relationship, resection margins, and surgeon volume on gastric cancer survival. Am J Surg 2003; 186: 23-7.

27. Liang Y, Wu L, Wang $X$, et al. The positive impact of surgeon specialization on survival for gastric cancer patients after surgery with curative intent. Gastric Cancer 2015; 18: 859-67.

Received: 2.12.2015

Accepted: 29.02.2016 